\title{
Mutational spectra of SARS-COV-2 isolated from animals
}

\author{
Ahmed Elaswad ${ }^{\text {Corresp., } 1}$, Mohamed Fawzy ${ }^{2}$, Shereen Basiouni ${ }^{3}$, Awad A. Shehata ${ }^{\text {Corresp. } 4,5}$ \\ ${ }^{1}$ Department of Animal Wealth Development, Faculty of Veterinary Medicine, Suez Canal University, Ismailia, Egypt \\ 2 Department of Virology, Faculty of Veterinary Medicine, Suez Canal University, Smailia, Egypt \\ 3 Clinical Pathology Department, Faculty of Veterinary Medicine, Benha University, Benha, Egypt \\ ${ }^{4}$ Avian and Rabbit Diseases Department, Faculty of Veterinary Medicine, Sadat City University, Sadat City, Egypt \\ 5 Research and Development Section, PerNaturam GmbH, Gödenroth, Germany \\ Corresponding Authors: Ahmed Elaswad, Awad A. Shehata \\ Email address: ahmed_elaswad@vet.suez.edu.eg, awad.shehata@vet.usc.edu.eg
}

Coronaviruses are ubiquitous and infect a wide spectrum of animals and humans. The newly emerged severe acute respiratory syndrome coronavirus-2 (SARS-CoV-2) has become a worldwide pandemic. To address the role that animals may play in the evolution of SARS-CoV-2, the full genome sequences of SARS-CoV-2 isolated from animals were compared with SARS-CoV-2 human isolates from the same clade and geographic region. Phylogenetic analysis of SARS-CoV-2 isolated from the cat, dog, mink, mouse, and tiger revealed a close relationship with SARS-CoV-2 human isolates from the same clade and geographic region with sequence identities of $99.94-99.99 \%$. The deduced amino acid sequence of spike (S) protein revealed the presence of a furin cleavage site $\left({ }^{682} \operatorname{RRAR} \boldsymbol{\nabla}^{685}\right)$, which did not differ among all SARS-CoV-2 isolates from animals and humans. SARS-CoV-2 isolates from minks exhibited two amino acid substitutions (G261D, A262S) in the Nterminal domain of S protein and four (L452M, Y453F, F486L, N501T) in the receptorbinding motif (RBM). In the mouse, the $S$ protein had two amino acid substitutions, one in the RBM (Q498H) and the other (N969S) in the heptad repeat 1 . SARS-CoV-2 isolated from minks furtherly exhibited three unique amino acid substitutions in the nucleocapsid (N)protein. In the cat, two unique amino acid substitutions were discovered in the $\mathrm{N}$ (T247I) and matrix (T175M) proteins. Additionally, SARS-CoV-2 isolated from minks possessed sixteen, four, and two unique amino acid substitutions in the open reading frame lab ( ORF1ab), ORF3a, and ORF6, respectively. Dog and cat SARS-CoV-2 isolates showed one and seven unique amino acid substitutions in ORFlab, respectively. Further studies may be necessary to determine the pathogenic significance of these amino acid substitutions to understand the molecular epidemiology and evolution of SARS-CoV-2. 
1

$3{ }^{1}$ Department of Animal Wealth Development, Faculty of Veterinary Medicine, Suez Canal

4 University, Ismailia, Egypt

$5{ }^{2}$ Department of Virology, Faculty of Veterinary Medicine, Suez Canal University, Ismailia, Egypt

$6{ }^{3}$ Clinical Pathology Department, Faculty of Veterinary Medicine, Benha University, Egypt

$7{ }^{4}$ Avian and Rabbit Diseases Department, Faculty of Veterinary Medicine, Sadat City University,

8 Sadat, Egypt

$9 \quad{ }^{5}$ Research and Development Section, PerNaturam GmbH, Gödenroth, Germany

11 Corresponding Authors:

$12 *$ Dr. Ahmed Elaswad,

Department of Animal Wealth Development, Faculty of Veterinary Medicine, Suez Canal

Email. dr_awadali_1@yahoo.com

**Dr. Awad A. Shehata

PerNaturam GmbH, 56290 Gödenroth, Germany 


\section{Abstract}

25 Coronaviruses are ubiquitous and infect a wide spectrum of animals and humans. The newly 26 emerged severe acute respiratory syndrome coronavirus-2 (SARS-CoV-2) has become a 27 worldwide pandemic. To address the role that animals may play in the evolution of SARS-CoV28 2, the full genome sequences of SARS-CoV-2 isolated from animals were compared with SARS29 CoV-2 human isolates from the same clade and geographic region. Phylogenetic analysis of 30 SARS-CoV-2 isolated from the cat, dog, mink, mouse, and tiger revealed a close relationship with 31 SARS-CoV-2 human isolates from the same clade and geographic region with sequence identities of $99.94-99.99 \%$. The deduced amino acid sequence of spike (S) protein revealed the presence of

33 a furin cleavage site $\left({ }^{682} \mathrm{RRAR} \boldsymbol{\nabla}^{685}\right)$, which did not differ among all SARS-CoV-2 isolates from 34 animals and humans. SARS-CoV-2 isolates from minks exhibited two amino acid substitutions 35 (G261D, A262S) in the N-terminal domain of S protein and four (L452M, Y453F, F486L, N501T) 36 in the receptor-binding motif(RBM). In the mouse, the S protein had two amino acid substitutions, 37 one in the RBM $(\mathrm{Q} 498 \mathrm{H})$ and the other $(\mathrm{N} 969 \mathrm{~S})$ in the heptad repeat 1. SARS-CoV-2 isolated 38 from minks furtherly exhibited three unique amino acid substitutions in the nucleocapsid (N) 39 protein. In the cat, two unique amino acid substitutions were discovered in the N (T247I) and matrix (T175M) proteins. Additionally, SARS-CoV-2 isolated from mink possessed sixteen, four, and two unique amino acid substitutions in the open reading frame 1ab (ORF1ab), ORF3a, and ORF6, respectively. Dog and cat SARS-CoV-2 isolates showed one and seven unique amino acid substitutions in ORF1ab, respectively. Further studies may be necessary to determine the 44 pathogenic significance of these amino acid substitutions to understand the molecular epidemiology and evolution of SARS-CoV-2. 
47 Keywords: Alignment, animals, evolution, phylogenetic analysis, mink, SARS-CoV-2, and 48 sequencing

\section{Introduction}

50 The outbreak of the novel coronavirus disease 2019 (COVID-19) caused by the severe acute 51 respiratory syndrome coronavirus-2 (SARS-CoV-2) has been reported in Wuhan City, Hubei 52 Province, China, and posed unprecedented challenges to global health. Despite the ongoing efforts 53 to control the COVID-19 outbreak, the disease is still spreading worldwide with increasing 54 numbers of infected cases and deaths. The World Health Organization (WHO) officially declared 55 it as a pandemic on 11 March 2020 (Wu et al. 2020; Zhou et al. 2020).

56 SARS-CoV-2 belongs to the order Nidovirales, suborder Cornidovirineae, family Coronaviridae, 57 subfamily Orthocoronavirinae, genus Betacoronavirus, and subgenus Sarbecovirus. The virus is 58 enveloped with a single-stranded positive-sense RNA genome of 29,903 nucleotides. SARS-CoV2 has a monopartite genome that consists of two untranslated regions (5' and 3' UTRs) and 11 open reading frames (ORFs) encoding 27 proteins. ORF1ab constitutes the first two-thirds of the genome (21,290 nucleotides) and encodes 16 non-structural proteins (nsp1-nsp16). The last third

62 of the genome encodes four structural and six accessory proteins. The structural proteins are the 63 Spike (S), Envelope (E), Matrix (M), and Nucleocapsid (N) proteins, while the accessory proteins 64 include the ORF3a, ORF6, ORF7a, ORF7b, ORF8, and ORF10 (Chan et al. 2020).

65 The N protein coils the RNA segment into a helical nucleocapsid that is incorporated into a virion 66 of icosahedral symmetry, whereas the $M$ and $E$ proteins are required for virus morphogenesis, 67 assembly, and budding (Paraskevis et al. 2020). The S glycoprotein (1273 aa) is a fusion viral 68 protein that consists of two subunits: S1 (681 aa) and S2 (588 aa). The S1 subunit comprises a 69 signal peptide (SP), an N-terminal domain (NTD), and a receptor-binding domain (RBD) that 
70 interacts with the angiotensin-converting enzyme 2 (ACE2) (Hoffmann et al. 2020; Letko et al. ;

71 Walls et al. 2020; Zhao et al. 2020). The S2 subunit comprises a fusion protein (FP) that mediates

72 membrane fusion and two heptad repeats known as HR1 and HR2, which form the coiled structures

73 surrounded by the protein ectodomain. A furin cleavage site (RRAR $\nabla$ ) for furin proteases exists

74 between the interface of S1 and S2 subunits of SARS-CoV-2 but not SARS-CoV (Canrong et al.

75 2020; Coutard et al. 2020). It mediates the initial attachment of the virus to the host-cell receptors

76 and subsequent fusion with the cell membrane allowing virus entry. Like SARS-CoV, SARS-CoV-

772 binds to ACE2 for cell entry as mediated by the viral surface $\mathrm{S}$ glycoprotein (Hoffmann et al.

78 2020; Walls et al. 2020; Yan et al. 2020; Zhou et al. 2020). Subsequently, the S protein is cleaved

79 by the transmembrane serine protease 2 (TMPRSS2) to S1 and S2 subunits (Hoffmann et al. 2020)

80 allowing the entry of the virion core.

81 There is a broad acceptance that SARS-CoV-2 has an animal origin, although the animal reservoir

82 has not yet been identified (Abdel-Moneim \& Abdelwhab 2020). Bats may be considered a 83 potential reservoir host for SARS-CoV-2 since they are the reservoir of several SARS related 84 coronaviruses. One of these viruses is the horseshoe bat (Rhinolophus affinis) coronavirus 85 RaTG13, which shares a high identity (96.3\%) with SARS-CoV-2 at the genome level (Helmy et 86 al. 2020). Wong and others (Wong et al. 2020) suggested that pangolin might be the intermediate 87 host as it shares $98 \%$ identity with SARS-CoV-2 at the receptor-binding motif(RBM) of S protein. 88 The receptor recognition by the $\mathrm{S}$ glycoprotein is the major determinant of host range, tissue 89 tropism, and pathogenesis of coronaviruses. Human-to-human transmission has been confirmed 90 even from asymptomatic carriers and pre-symptomatic infected persons (Rothe et al. 2020; Zou et 91 al. 2020). Several cases of SARS-CoV-2 infections in animal hosts (cat, dog, mink, and tiger) have 92 been reported (Gollakner \& Capua 2020; Tazerji et al. 2020), although none of them developed 
93 typical clinical features as COVID-19 patients. The dynamics of the disease concerning the

94 transmission of the virus from humans to animals and vice versa requires further explanation.

95 Additionally, there is inadequate information on whether animals have a role in the evolution of

96 SARS-CoV-2. Hence, the mutation rate could drive viral evolution and genome variability, thereby

97 enabling viruses to escape host immunity and develop drug resistance. In the present study, the

98 genetic diversity and mutations in SARS-CoV-2 isolated from cats, dogs, mouse, minks, and tiger

99 were characterized and compared with human isolates to investigate the mutational spectra that

100 might play a role in the virus evolution, transmission, and pathogenesis.

\section{Materials and methods}

\section{SARS-CoV-2 sequences used for genetic analysis}

103 A total of 310 complete coronavirus genomes were used in the current study. All genomes were

104 downloaded from the Global Initiative on Sharing All Influenza Data (GISAID) and the National

105 Center for Biotechnology Information (NCBI) databases. These genomes included: 157 genomes

106 for SARS-CoV-2 isolates from animals [cat $(n=6), \operatorname{dog}(n=2)$, mink $(n=147)$, mouse $(n=1)$, and

107 tiger $(\mathrm{n}=1)], 150$ human SARS-CoV-2 isolates from Belgium, China, England, France, Hong

108 Kong, Netherlands, Spain, and the USA, SARS-CoV-2 reference genome (Wuhan-Hu-1), 109 pangolin coronavirus (MT121216.1), and bat coronavirus RaTG13 (MN996532.1). The genomes

110 of human isolates were selected based on three conditions: (1) They belonged to the same clade

111 (GISAID clades) as the animal isolates, (2) They originated from the same place (country), and

112 (3) They were collected for sequencing at the same time as animal isolates whenever possible. For 113 example, the SARS-CoV-2 isolate from the tiger was collected in April 2020 from New York,

114 USA. Therefore, we selected 30 human isolates from New York collected in the same month and

115 from the same clade $(\mathrm{GH})$. For each animal species, 30 human SARS-CoV-2 genomes were 
116 selected for comparison. Further data about the 310 genomes used in the current study including

117 the virus isolate, accession number, collection date, clade, genome length, host, geographic area,

118 and percentage of ambiguous bases $(\% \mathrm{~N})$ are listed in Supplementary Table 1.

\section{Genetic analysis}

\section{Identification of mutations}

121 Only the coding gene sequences were used for the analysis. Sequences were aligned using Kalign3

122 (Lassmann 2020), and the single nucleotide polymorphisms were analyzed using the SNiPlay

123 pipeline (Dereeper et al. 2015). The protein sequences were predicted using MEGAX(Kumar et

124 al. 2018).

125 Mutations were investigated in all genes of animal isolates and compared to human isolates. Only 126 differences between animal or animal-human isolates were reported. The frequency of a mutation 127 was calculated as follows:

$$
\text { Frequency of a mutation }=\frac{\text { The number of genomes that have the mutation }}{\text { The total number of genomes }} \times 100
$$

All mutations with their frequency and effects on the amino acid sequences are reported in Supplementary Table 2 . Mutations that existed in more than $2 \%$ of the studied genomes for a given animal species are reported in the main tables (Table 1, 2, and 3). Variations that existed only sequence was determined. Some viral genomes such as isolates from the cat, dog, mink, and human on the percentage of Ns in each of the studied genomes). These ambiguous genomic regions were not used for mutation analysis for those species. 
140 Evolutionary divergence

141 The pairwise genetic distances (Supplementary Table 3) were calculated in MEGAX using the

142 Maximum Composite Likelihood model (Tamura et al. 2004). The genetic distances were 143 estimated for forty-two sequences representing SARS-CoV-2 isolates from humans and animals, 144 pangolin coronavirus (MT121216.1), and bat coronavirus RaTG13 (MN996532.2). The sequence 145 identity percentage was calculated from the pairwise genetic distance as follows:

146 Identity $\%=100-($ pairwise distance $x 100)$

\section{Phylogenetic analysis}

149 Forty SARS-CoV-2 genomes were used for phylogenetic analysis (Figure 1). The phylogenetic 150 tree was constructed based on the coding sequences of all genes. The 3' UTR, 5' UTR, and non151 coding sequences were excluded. Sequences were aligned using Kalign3 (Lassmann 2020). The 152 phylogenetic tree was constructed in IQ-TREE (Nguyen et al. 2015) using the maximum likelihood 153 method, ModelFinder (to identify the best fitting model (s)), and ultrafast bootstrap approximation 154 (1000 replicates). The best-fitting models were TN (Tamura-Nei) + F (Felsenstein) + I (proportion 155 of invisible sites). The tree was drawn to scale with branch length representing the number of 156 substitutions per site. The tree was visualized in MEGAX (Kumar et al. 2018) and rooted on the 157 midpoint.

158 Results

159 Sequence analysis of SARS-CoV-2 isolated from animals

160 The SARS-CoV-2 isolated from animals had the same genome organization and encoded the same 161 proteins as human isolates. The nucleotide sequence identities of the whole genome of SARS- 
162 CoV-2 animal isolates were compared with different SARS-CoV-2 human isolates

163 (Supplementary Table 3). The homology analyses of human coronaviruses with hCoV-19/tiger,

164 hCoV-19/mouse/Harbin, hCoV-19/mink, hCoV-19/cat, hCoV-19/canine (dog, EPI_ISL_450403)

165 showed a percent identity of $99.7-100 \%, 99.95-99.98 \%, 99.94-99.96 \%, 99.97-99.98 \%$, and $99.97-$

$16699.99 \%$ with other human SARS-CoV-2 isolates, respectively. The phylogenetic tree was

167 reconstructed based on the coding sequences of the whole genome (Figure 1). Most animal and 168 human SARS-CoV-2 isolates from the same GISAID clade clustered together. For example, the 169 clade GR cluster contained the sequences from the dog, cats, and humans (all belong to the clade 170 GR) regardless of their geographic region. Similar results were obtained for isolates from the mink, 171 tiger, and mouse. In the case of clade G, human and animal isolates from the Netherlands clustered 172 separately from other countries (Figure 1).

\section{Mutational spectra of non-structural proteins (ORF1ab)}

174 Sequence analysis of the ORF1ab gene of the studied isolates from animals revealed a total of 133 175 substitutions, 108 of which were unique in animals (Supplementary Table 2). Most of the unique 176 mutations (98) occurred in mink isolates, while 2, 6, and 2 mutations were reported in dog, cat, 177 and mouse isolates, respectively. Of the 133 mutations, 79 were non-synonymous (changed amino 178 acid sequence), while 54 were synonymous.

179 To summarize the results and exclude less frequent mutations, we set a threshold of $2 \%$ for 180 reporting mutations in Tables 1,2 , and 3 . Table 1 contains the most common amino acid 181 substitutions (above the threshold) of the non-structural proteins encoded by the ORF1ab gene of 182 SARS-CoV-2. The nsp2 exhibited six unique amino acid substitutions, one in cat isolate (H388Y) 183 and five in mink isolates (E352Q, A372V, R398C, A405T, and E743V), while nsp3 (Papain-like 184 proteinase domain) revealed three (D953Y, V1052I, and K1202N), one (D2101G), and four 
185 (P1096L, H1113Y, I1508V, and M1588K) unique amino acid substitutions in SARS-CoV-2 186 isolates from the cat, dog, and mink, respectively. The nsp5 (3C-like proteinase domain) had two 187 unique amino acid substitutions, one in cat isolate (I3512T) and the other in mink isolate (I3522V). 188 Moreover, nsp9 (RNA/DNA binding activity) and nsp15 (Poly(U) specific endoribonuclease) of 189 SARS-CoV-2 isolated from the mink exhibited one unique amino acid substitution at (G4177E or 190 R) and (A6544T), respectively. In addition, nsp10 of SARS-CoV-2 isolated from the cat displayed 191 one unique amino acid substitution (K4377E), while nsp12 (RNA-dependent RNA polymerase, $192 \mathrm{RdRp}$ ) exhibited three unique amino acid substitutions, one for the cat (T4418I) and two for the 193 mink (M4588I and T5195I). Two unique amino acid substitutions (I5582V and A5770D) were 194 recorded in mink isolate for nsp13 (helicase). Finally, the frequency of mutations in nsp1, nsp4, 195 nsp6, nsp7, nsp8, nsp11, nsp14, and nsp16 of ORF1ab gene was less than the 2\% threshold, 196 therefore not listed in Table 1.

\section{Mutational spectra of structural proteins}

198 Sequence analysis of SARS-CoV-2 structural genes from animals revealed several mutations in 199 S, M, and N gene, while no mutations were detected in the E gene.

\section{Mutational spectra of Spike (S) protein}

201 The spike gene of animals SARS-CoV-2 consists of 3,822 nucleotides $(21,563-25,384)$ that encode

202 1,273 amino acids. The domain structures and critical ACE2-binding residues of S protein from 203 animal SARS-CoV-2 are illustrated in Figure (2). The analysis of mutations in the S gene of the 204 studied isolates from animals revealed a total of 25 unique substitution mutations, 22 of which 205 occurred in mink isolates (Supplementary Table 2). The cat isolates had one unique substitution, 206 while the mouse had two unique substitutions and one deletion mutation. No mutations were 207 identified in the $\mathrm{S}$ gene from the dog or tiger isolates. Of the 25 substitutions, 17 were non208 synonymous, while nine substitutions were synonymous (Supplementary Table 2). 
209 The non-synonymous mutations reported for spike protein in Table (2) were distributed as follows:

210 one in the signal peptide (SP), two in the N-terminal domain (NTD), six in the receptor-binding

211 domain (RBD), one downstream of the RBD (D614G), and one in the heptad repeat 1 (HR1) (Refer

212 to Figure 2 for the map of spike protein). In the mouse isolate, two unique amino acid substitutions

213 (Q498H and N969S) were identified, with one of them (Q498H) located within the RBM (Figure

214 3). Fifteen unique mutations were identified in mink isolates (Supplementary Table 2), four of 215 which (L452M, Y453F, F486L, N501T) were located within the RBM of S protein (Figure 2,

216 Figure 3, Table 2). The deletion of five amino acid residues in the isolate from the mouse was

217 close to the furin cleavage site. No mutations were identified at the furin cleavage site of SARS-

$218 \mathrm{CoV}-2$ isolates from other animals. All mutations reported for spike protein in Table (2) are unique

219 for animal isolates except the mutation in the SP for the dog (L8V). The position and structure of 220 each amino acid substitution in the RBM compared to normal residues are illustrated in Figure (3).

\section{Mutational spectra of matrix (M) protein}

222 The M gene of SARS-CoV-2 isolated from animals is composed of 669 nucleotides $(26,523-$

223 27,191) that encode 222 amino acids. The M protein consists of the $\mathrm{N}$-terminal domain that is

224 present on the virion surface, and the C-terminal domain located on the interior surface of the

225 virion. Analysis of mutations in the $\mathrm{M}$ gene of the studied animal isolates revealed a total of six

226 unique nucleotide substitution mutations, five of which occurred in mink isolates and one in the

227 cat isolate (Supplementary Table 2). Four of the six mutations were non-synonymous, while two

228 were synonymous. No mutations were recorded in the $M$ gene of the dog, mouse, or tiger

229 (Supplementary Table 2). The frequency of the non-synonymous mutations was below the 2\%

230 threshold, therefore not reported in Table (2) except the T175M substitution in the cat isolate $231(16.7 \%)$. 


\section{Mutational spectra of nucleocapsid (N) protein}

233 The N gene of SARS-CoV-2 isolated from animals is composed of 1,260 nucleotides $(28,274-$

23429,533 ) that encode 419 amino acids. Analysis of N protein sequences from animal SARS-CoV-2

235 isolates revealed 19 unique mutations, 17 of which occurred in mink and two in cat (Supplementary

236 Table 2). No mutations were detected in the $\mathrm{N}$ gene of the dog, mouse, or tiger. Twelve of the 19

237 mutations were non-synonymous (Supplementary Table 2). SARS-CoV-2 isolated from the mink

238 exhibited three unique amino acid substitutions (R41L, P80L, and P199Q) with a frequency of

$2392.7 \%$, while SARS-CoV-2 isolated from the cat had one unique amino acid substitution (T247I)

240 with a frequency of $16.7 \%$ (Table 2 ).

241 Mutational spectra of accessory proteins

242 SARS-CoV-2 genome has six accessory genes that encode six accessory proteins; ORF3a (275

243 aa), ORF6 (61 aa), ORF7a (121 aa), ORF7b (43 aa), ORF8 (121 aa), and ORF10 (38 aa). No

244 mutations were identified in ORF10, while sixteen, three, two, one, and three nucleotide

245 substitutions were discovered in ORF3a, ORF6, ORF7a, ORF7b, and ORF8 of mink isolates,

246 respectively (Supplementary Table 2). In addition, 134-nucleotide deletion mutation, resulting in

247 the deletion of 45 amino acid residues, was identified in ORF7a of two mink isolates

248 (EPI_ISL_447623 and EPI_ISL_522991). Four unique amino acid substitution positions (H182L

249 or H182Y, L219V, G224C, T229I) within the ORF3a protein of mink isolates had a frequency of

250 more than 2\%. Also, two unique substitutions (R20S and K23S) in the ORF6 protein of the mink

251 isolates had a frequency of more than $2 \%$ (Table 3 ).

\section{Discussion}

253 The novel coronavirus (SARS-CoV-2) has been identified as the causative agent of the coronavirus 254 disease 2019 (COVID-19) outbreak in Wuhan City, Hubei province, China in December 2019 
255 (Huang et al. 2020; Zhou et al. 2020). Like other coronaviruses, the interspecies transmission of 256 SARS-CoV-2 is possible. Bats are the natural host of human coronaviruses 229E, SARS-CoV, 257 NL63, and MERS-CoV (Corman et al. 2015; Corman et al. 2016; Donaldson et al. 2010; Ge et al. 258 2013; Hu et al. 2015; Huynh et al. 2012; Samara \& Abdoun 2014; Tao et al. 2017), while rodents 259 are the natural host of HKU1 and OC43 (Cui et al. 2019). The intermediate hosts of both NL63 260 and HKU1 are not yet unidentified, while the intermediate hosts of 229E, OC43, SARS-CoV, and 261 MERS-CoV are camelids, bovines, palm civets, and dromedary camels, respectively (Corman et 262 al. 2015; Cui et al. 2019; Donaldson et al. 2010; Ge et al. 2013; Hu et al. 2015). This study aimed 263 to identify the genomic features that might be associated with interspecies jumping of SARS-CoV2642 between humans and animals. To this extent, SARS-CoV-2 genomes from different species 265 including humans, cats, dogs, mouse, minks, and tiger were fully characterized and compared with 266 geographically and phylogenetically close SARS-CoV-2 human isolates.

267 Phylogenetic analyses of hCoV-19/tiger, hCoV-19/mouse/Harbin, hCoV-19/mink, hCoV-19/cat, 268 and $\mathrm{hCoV}-19 / \mathrm{dog}$ revealed a close relationship (99.7-100\%) with SARS-CoV-2 human isolates. It 269 is speculated that bats are the natural source of SARS-CoV-2, hence the phylogenetic analysis of 270 SARS-CoV-2 revealed a nucleotide homology of 96.3\% with the bat CoV RaTG13 (Zhou et al. 271 2020). Additionally, the nucleotide sequence homology between pangolin and analyzed human 272 SARS-CoV-2 isolates in this study is $89 \%$. Although pangolin could not be excluded as one of the 273 intermediate animal hosts of SARS-CoV-2 (Lam et al. 2020), a direct transmission of pangolin 274 SARS-CoV-2 might not be possible due to the sequence divergence.

275 Generally, coronaviruses can easily cross species barriers. There are three main reasons for 276 interspecies transmission of coronaviruses; firstly, the high mutation rates ( $\mathrm{Su}$ et al. 2016), 277 although the mutation rate of SARS-CoV-2 is lower than SARS-CoV (Ye et al. 2020). Secondly, 
278 the large RNA genome of coronaviruses, which increases the incidence of mutations and 279 recombination leading to the emergence of novel CoVs (Ye et al. 2020). Thirdly, the interaction 280 of coronaviruses with different ACE2 receptors (Bolles et al. 2011). The SARS-CoV and HCoV281 NL63 bind with ACE2 for interspecies transmission (Graham \& Baric 2010; Hofmann et al. 2005). 282 However, HCoV-229E and HCoV-OC43 use aminopeptidase N (APN) and 9-O-acetylated sialic 283 acid (9-O-Ac-Sia) receptors, respectively, which helps successful adaptation in humans after 284 interspecies transmission from their animal hosts (Huang et al. 2015; Liu et al. 2020). Although 285 SARS-CoV-2 uses the ACE2 receptor for host cell entry (Hoffmann et al. 2020; Zhou et al. 2020), 286 it remains unclear whether any other coreceptor might be required for its transmission.

287 In the present study, sequence analysis of the SARS-CoV-2 revealed several unique amino acid 288 substitutions within the $\mathrm{S}, \mathrm{M}, \mathrm{N}$, and nsps proteins. These mutations may indicate that the virus is 289 not yet adapted to these animals. (Duffy 2018) reported that the mutation rate is often high when 290 coronaviruses are not well adapted to their hosts. Several amino acid substitutions may not 291 significantly switch the amino acid properties as the involved amino acid residues were either from 292 the same class or shared some properties. In S protein, for example, L452M involved leucine and 293 methionine, and both are neutral and hydrophobic. Similarly, Y453F involved tyrosine and 294 phenylalanine, and both are hydrophobic and aromatic. However, Q498H in mouse isolate may 295 have a significant change in the properties of the amino acid residues because glutamine is neutral 296 while histidine is positively charged, and both have significant differences in the structure of the 297 side chain.

298 Mutations in the S protein could change the tropism of the virus, pathogenicity, and interspecies 299 transmission (Wan et al., 2020). In our study, several unique mutations were found in the SP, NTD, 300 RBD, downstream to RBD, and in the HR1 of S protein. Ortega and others (Ortega et al. 2020) 
301 reported that slight modifications of some residues within RBD of SARS-CoV-2 could improve

302 the interaction with the human cellular receptors. The D614G mutation downstream of the RBD 303 could be associated with higher transmission, pathogenicity, and evasion of immune interventions

304 (Happi et al. 2020; Korber et al.) 2020). It was found that K479N and S487T of SARS-CoV are

305 associated with human ACE2 receptor recognition. These amino acids are corresponding to Q493

306 and N501 in SARS-CoV-2, respectively (Ortega et al. 2020). In our study, all analyzed SARS-

307 CoV-2 from animals had Q493 and N501 except mink isolates which had N501T (Figure 2, 3).

308 However, the question whether other reported mutations contribute to further adaptation, and 309 subsequently impact the virus pathogenicity require further investigation. Computational models 310 and data have identified additional mutations that might further strengthen the binding affinity of

311 SARS-CoV-2 to ACE2 receptors (Wan et al. 2020). (Yao et al. 2020) found that S protein 312 mutations of SARS-CoV-2 are capable of changing its pathogenicity. Further studies are required 313 to investigate the impact of these mutations on virus evolution.

314 The N protein of SARS-CoV-2 consists of 1,260 nucleotides that encodes 419 amino acids. It is a 315 multifunction protein and an important determinant of the virus pathogenicity, viral transcription 316 efficiency, and coiling the RNA segment into a helical nucleocapsid incorporated into virion of 317 icosahedral symmetry (McBride et al. 2014; Paraskevis et al. 2020). In our study, the N protein 318 had four amino acid substitutions: three in mink isolates (R41L, P80L, and P199Q) with a 319 frequency of $2.7 \%$ each, and one in cat isolates (T247I) with a frequency of $16.7 \%$.

320 Generally, the nsps (nsp1-16) of coronaviruses play essential roles in virus replication (Lei et al. 321 2018; Zeng et al. 2018), polypeptide cleaving (Lei et al. 2018; Zhu et al. 2017), and inhibition of 322 host immune response (Lei et al. 2018; Shi et al. 2019; Zhu et al. 2017). The ORF1ab polyprotein 323 of SARS-CoV-2 plays an important role in viral RNA synthesis (Banerjee et al. 2020). In SARS 
$324 \mathrm{CoV}$, it was found that nsp2 binds to the host proteins (prohibitin 1 and prohibitin 2) which are 325 involved in several cellular functions including cell cycle progression, cell migration, cellular 326 differentiation, apoptosis, and mitochondrial biogenesis (Cornillez-Ty et al. 2009). Analysis of 327 ORF1ab nsp2 (638 aa from A181-G818) polyproteins of SARS-CoV-2 isolated from animals 328 revealed six characteristic mutations, one in cat $(\mathrm{H} 388 \mathrm{Y})$ and five in mink (E352Q, A372V, 329 R398C, A405T, and E743V) isolates. The impact of these mutations on the function of nsp2 and 330 virus evolution is still unknown, although stabilizing mutation falling in the 331 endosome-associated-protein-like domain of the nsp2 protein, could explain why SARS-CoV-2 is 332 more contagious than SARS-CoV (Angeletti et al. 2020).

333 The papain-like proteinase (PLpro) and 3C-like main protease (3CLpro) are encoded by nsp3 and 334 nsp5, respectively. Both PLpro and 3CLpro play a role in virus replication and antagonize the 335 host's innate immunity (Harcourt et al. 2004; Li et al. 2016). They are also a popular target for 336 antiviral drugs (Wu et al. 2020). Sequence analysis of the nsp3 and nsp5 of SARS-CoV-2 isolated 337 from animals revealed eight and three unique amino acid substitutions, respectively. The role of 338 these mutations in nsp3 on virus replication and susceptibility to antiviral drugs should be 339 investigated. The nsp3 mutation could explain the difference in pathogenicity between SARS$340 \mathrm{CoV}-2$ and SARS-CoV (Angeletti et al. 2020). Furthermore, unique mutations were found within 341 the nsp9, nsp10, nsp12, and nsp13. Although no direct evidence exists about their roles, continued 342 evidence-based analysis of evolutionary change is important.

343 Additionally, the ORF3a protein of coronaviruses showed a pro-apoptotic activity. The SARS$344 \mathrm{CoV}-2$ is less virulent than SARS-CoV due to diminished pro-apoptotic activity (Ren et al. 2020).

345 Herein, different mutations were found within ORF3a (Table 3, Supplementary Table 2). 
346 However, the impact of mutations within ORF3a of SARS-CoV-2 on the apoptotic activity and 347 consequently on the virus pathogenicity is unknown.

348 In conclusion, although the dynamics of SARS-CoV-2 transmission from humans to animals and 349 vice versa is still unclear, further human-animals interface is possible due to the similarity of ACE2 350 receptors in humans and some animal species. In the present study, unique amino acid substitutions 351 were reported in almost all animal SARS-CoV-2 proteins such as the ORF1ab, S glycoprotein 352 (including critical ACE2-binding sites), ORF3a, and N proteins. Our study draws the attention of 353 scientists worldwide on the role of mink as an animal host to SARS-CoV-2 due to several unique 354 amino acid substitutions recorded in its proteins (specially S protein) that might play a role in the 355 virus evolution, pathogenesis and transmission to human. This study also recommends continuous 356 molecular surveillance of SARS-CoV-2 animal isolates. Also, it is essential to furtherly investigate 357 if these mutations could impact the virus evolution, including virus adaptation, changes in the 358 pathogenicity, and the emergence of drug-resistance viral phenotypes.

359

360

361

362 363

364

365 366 367 368 369

\section{Acknowledgment}

We gratefully acknowledge the authors, originating, and submitting laboratories of the sequences from the GISAID's EpiCoVTM Database and NCBI on which this study is based.

\section{Author Contributions}

Conceptualization: Shehata AA, Fawzy M, and Elsawad A.; methodology: Elsawad A, Fawzy M, Basiouni S, and Shehata AA; software: Elsawad A: validation: Elsawad A, Shehata AA; formal analysis: Elsawad A, Fawzy M, Basiouni S, and Shehata AA.; data curation and writing-original draft preparation, review and editing: Elsawad A, Fawzy M, Basiouni S, and Shehata AA; visualization, investigation, and supervision, Shehata AA. 
370

\section{Funding}

372 This research received no external funding.

373

374 Conflict of Interest

375 Authors declare that there is no conflict of interest

376

377 List of figures

378 Figure 1. Phylogenetic tree of 40 SARS-CoV-2 genomes from animals and humans. Each sequence

379 is reported by the accession number, host, and geographic region (country). Different clades are

380 labelled and highlighted differently. The tree was constructed in IQ-TREE using the maximum

381 likelihood method, ModelFinder, and ultrafast bootstrap approximation (1000 replicates). The tree

382 is rooted on midpoint. Branch lengths are measured in the number of substitutions per site. The 383 percentage of replicate trees in which the associated viruses clustered together in the bootstrap test 384 is represented by the numbers above the branches. Bootstrap values less than $50 \%$ are not shown. 385

386 Figure 2. Map of SARS-CoV-2 spike protein structure. This includes from the N-terminal end $387(\mathrm{NH} 2)$ to the $\mathrm{C}$-terminal end $(\mathrm{COOH})$, the signal peptide $(\mathrm{SP})$, N-terminal domain (NTD), 388 receptor-binding domain $(\mathrm{RBD})$, receptor-binding motif (RBM), fusion peptide (FP), heptad repeat 1 (HR1), heptad repeat 2 (HR2), transmembrane domain (TM), and intracellular domain 390 (IC). The spike protein consists of two subunits: S1 and S2 that are cleaved at the furin cleavage 391 site. The differences in the spike amino acid sequences from animal isolates compared to SARS-

392 CoV-2 reference (Wuhan-Hu-1 isolate), pangolin coronavirus MP789, and bat coronavirus 
393 RaTG13 are marked by the red rectangles. The multiple sequence alignment is presented for the

394 RBM (bottom) and the furin cleavage site (top).

395

396 Figure 3. Amino acid substitutions in the receptor-binding motif (RBM) of SARS-CoV-2 S

397 protein from animal isolates. Only monomeric partial structure of S protein is shown where the 398 receptor-binding domain $(\mathrm{RBD})$ is purple, $\mathrm{RBM}$ is blue, and the substitution sites are red. This 399 structure is based on Protein Data Bank (PDB) reference structure 6ZB4. In each mutation site, 400 the side chains of the amino acid residues are shown for normal (A) and mutated (B) RBM.

401

402

403

404

405

406

407

408

409

410

411

412

413

414

415

\section{References}

Abdel-Moneim AS, and Abdelwhab EM. 2020. Evidence for SARS-CoV-2 infection of animal hosts. Pathogens 9:529. https://doi.org/10.3390/pathogens9070529.

Angeletti S, Benvenuto D, Bianchi M, Giovanetti M, Pascarella S, and Ciccozzi M. 2020. COVID-2019: the role of the nsp2 and nsp3 in its pathogenesis. Journal of medical virology 92:584-588.

Banerjee S, Seal S, Dey R, Mondal KK, and Bhattacharjee P. 2020. Mutational spectra of SARS-CoV-2 orflab polyprotein and signature mutations in the United States of America. Journal of medical virology:1-8.

Bolles M, Donaldson E, and Baric R. 2011. SARS-CoV and emergent coronaviruses: viral determinants of interspecies transmission. Current opinion in virology 1:624-634.

Canrong W, Yang Y, Yang L, Zhang P, Wang Y, and Wang Q. 2020. Furin, a potential therapeutic target for COVID-19. ChinArxiv 23:101642.

Peer] reviewing PDF | (2020:07:51554:1:1:NEW 18 Nov 2020) 
416 Chan JF-W, Kok K-H, Zhu Z, Chu H, To KK-W, Yuan S, and Yuen K-Y. 2020. Genomic

417 characterization of the 2019 novel human-pathogenic coronavirus isolated from a patient

418 with atypical pneumonia after visiting Wuhan. Emerging microbes \& infections 9:221-

419236.

420 Corman VM, Baldwin HJ, Tateno AF, Zerbinati RM, Annan A, Owusu M, Nkrumah EE,

421 Maganga GD, Oppong S, and Adu-Sarkodie Y. 2015. Evidence for an ancestral

422 association of human coronavirus 229E with bats. Journal of virology 89:11858-11870.

423

424

425

426

427

428

429

430

431

432

433

434

435

436

437

Corman VM, Eckerle I, Memish ZA, Liljander AM, Dijkman R, Jonsdottir H, Ngeiywa KJJ, Kamau E, Younan M, and Al Masri M. 2016. Link of a ubiquitous human coronavirus to dromedary camels. Proceedings of the National Academy of Sciences 113:9864-9869.

Cornillez-Ty CT, Liao L, Yates JR, Kuhn P, and Buchmeier MJ. 2009. Severe acute respiratory syndrome coronavirus nonstructural protein 2 interacts with a host protein complex involved in mitochondrial biogenesis and intracellular signaling. Journal of virology 83:10314-10318.

Coutard B, Valle C, de Lamballerie X, Canard B, Seidah N, and Decroly E. 2020. The spike glycoprotein of the new coronavirus 2019-nCoV contains a furin-like cleavage site absent in $\mathrm{CoV}$ of the same clade. Antiviral research 176:104742.

Cui J, Li F, and Shi Z-L. 2019. Origin and evolution of pathogenic coronaviruses. Nature Reviews Microbiology 17:181-192.

Dereeper A, Homa F, Andres G, Sempere G, Sarah G, Hueber Y, Dufayard J-F, and Ruiz M. 2015. SNiPlay3: a web-based application for exploration and large scale analyses of genomic variations. Nucleic Acids Research 43: 295-300. 
438 Donaldson EF, Haskew AN, Gates JE, Huynh J, Moore CJ, and Frieman MB. 2010.

439 Metagenomic analysis of the viromes of three North American bat species: viral diversity

$440 \quad$ among different bat species that share a common habitat. Journal of virology 84:13004-

$441 \quad 13018$.

442 Duffy S. 2018. Why are RNA virus mutation rates so damn high? PLoS biology 16:e3000003.

443 Ge X-Y, Li J-L, Yang X-L, Chmura AA, Zhu G, Epstein JH, Mazet JK, Hu B, Zhang W, and

444 Peng C. 2013. Isolation and characterization of a bat SARS-like coronavirus that uses the $445 \quad$ ACE2 receptor. nature 503:535-538.

446 Gollakner R, and Capua I. 2020. Is COVID-19 the first pandemic that evolves into a panzootic?

447 Veterinaria Italiana 56:11-12.

448 Graham RL, and Baric RS. 2010. Recombination, reservoirs, and the modular spike: mechanisms 449 of coronavirus cross-species transmission. Journal of virology 84:3134-3146.

450 Happi C, Ihekweazu C, Oluniyi P, and Olawoye I. 2020. SARS-CoV-2 genomes from Nigeria 451 reveal community transmission, multiple virus lineages and spike protein mutation associated with higher transmission and pathogenicity. Genome Reports.

453 Virological. 2020 http://virological.org/t/sars-cov-2-genomes-from-nigeria-revealcommunity-transmission-multiple-virus-lineages-and-spike-protein-mutation-associatedwith-higher-transmission-and-pathogenicity/494 Last accessed on October, 2020 and Baker SC. 2004. Identification of severe acute respiratory syndrome coronavirus replicase products and characterization of papain-like protease activity. Journal of virology 78:13600-13612. 
460 Helmy YA, Fawzy M, Elaswad A, Sobieh A, Kenney SP, and Shehata AA. 2020. The COVID4619 pandemic: a comprehensive review of taxonomy, genetics, epidemiology, diagnosis, 462 treatment, and control. Journal of Clinical Medicine 9:1225.

463 Hoffmann M, Kleine-Weber H, Schroeder S, Krüger N, Herrler T, Erichsen S, Schiergens TS, 464 Herrler G, Wu N-H, and Nitsche A. 2020. SARS-CoV-2 cell entry depends on ACE2 and 465 TMPRSS2 and is blocked by a clinically proven protease inhibitor. Cell 181:271-280.

466 Hofmann H, Pyrc K, Van Der Hoek L, Geier M, Berkhout B, and Pöhlmann S. 2005. Human 467 468 coronavirus NL63 employs the severe acute respiratory syndrome coronavirus receptor for cellular entry. Proceedings of the National Academy of Sciences 102:7988-7993.

Hu B, Ge X, Wang L-F, and Shi Z. 2015. Bat origin of human coronaviruses. Virology journal 470 12:1-10.

471 Huang C, Wang Y, Li X, Ren L, Zhao J, Hu Y, Zhang L, Fan G, Xu J, and Gu X. 2020. Clinical 472 473 features of patients infected with 2019 novel coronavirus in Wuhan, China. The lancet $395: 497-506$.

Huang X, Dong W, Milewska A, Golda A, Qi Y, Zhu QK, Marasco WA, Baric RS, Sims AC, and Pyrc K. 2015. Human coronavirus HKU1 spike protein uses O-acetylated sialic acid 476 as an attachment receptor determinant and employs hemagglutinin-esterase protein as a receptor-destroying enzyme. Journal of virology 89:7202-7213.

478 Huynh J, Li S, Yount B, Smith A, Sturges L, Olsen JC, Nagel J, Johnson JB, Agnihothram S, 479 and Gates JE. 2012. Evidence supporting a zoonotic origin of human coronavirus strain NL63. Journal of virology 86:12816-12825. 
481 Korber B, Fischer W, Gnanakaran S, Yoon H, Theiler J, and Abfalterer W. \& Partridge, DG 482 (2020). Spike mutation pipeline reveals the emergence of a more transmissible form of 483 SARS-CoV-2. BioRxiv.

484

485

486

487

488

489

490

491

492

493

494

495

496

497

498

499

500

501

502

503

Kumar S, Stecher G, Li M, Knyaz C, and Tamura K. 2018. MEGA X: molecular evolutionary genetics analysis across computing platforms. Molecular biology and evolution 35:15471549.

Lam TT-Y, Jia N, Zhang Y-W, Shum MH-H, Jiang J-F, Zhu H-C, Tong Y-G, Shi Y-X, Ni X-B, and Liao Y-S. 2020. Identifying SARS-CoV-2-related coronaviruses in Malayan pangolins. nature 583:282-285.

Lassmann T. 2020. Kalign 3: multiple sequence alignment of large datasets. Bioinformatics. p 1928-1929.

Lei J, Kusov Y, and Hilgenfeld R. 2018. Nsp3 of coronaviruses: Structures and functions of a large multi-domain protein. Antiviral research 149:58-74.

Letko M, Marzi A, and Munster V. Functional assessment of cell entry and receptor usage for SARS-CoV-2 and other lineage B betacoronaviruses. Nat Microbiol 2020; 5: 562-9.

Li S-W, Wang C-Y, Jou Y-J, Huang S-H, Hsiao L-H, Wan L, Lin Y-J, Kung S-H, and Lin C-W. 2016. SARS coronavirus papain-like protease inhibits the TLR7 signaling pathway through removing Lys63-linked polyubiquitination of TRAF3 and TRAF6. International journal of molecular sciences 17:678.

Liu DX, Liang JQ, and Fung TS. 2020. Human Coronavirus-229E,-OC43,-NL63, and-HKU1. Reference Module in Life Sciences:1-13.

McBride R, Van Zyl M, and Fielding BC. 2014. The coronavirus nucleocapsid is a multifunctional protein. Viruses 6:2991-3018. 
504 Nguyen L-T, Schmidt HA, Von Haeseler A, and Minh BQ. 2015. IQ-TREE: a fast and effective 505 stochastic algorithm for estimating maximum-likelihood phylogenies. Molecular biology $506 \quad$ and evolution 32:268-274.

507 Ortega JT, Serrano ML, Pujol FH, and Rangel HR. 2020. Role of changes in SARS-CoV-2 spike 508 protein in the interaction with the human ACE2 receptor: An in silico analysis. EXCLI 509 journal 19:410.

510

511

512

513

514

515

516

517

518

519

520

521

522

523

524

Paraskevis D, Kostaki EG, Magiorkinis G, Panayiotakopoulos G, Sourvinos G, and Tsiodras S. 2020. Full-genome evolutionary analysis of the novel corona virus (2019-nCoV) rejects the hypothesis of emergence as a result of a recent recombination event. Infection, Genetics and Evolution 79:104212.

Ren Y, Shu T, Wu D, Mu J, Wang C, Huang M, Han Y, Zhang X-Y, Zhou W, and Qiu Y. 2020. The ORF3a protein of SARS-CoV-2 induces apoptosis in cells. Cellular \& molecular immunology:1-3.

Rothe C, Schunk M, Sothmann P, Bretzel G, Froeschl G, Wallrauch C, Zimmer T, Thiel V, Janke C, and Guggemos W. 2020. Transmission of 2019-nCoV infection from an asymptomatic contact in Germany. New England Journal of Medicine 382:970-971.

Samara EM, and Abdoun KA. 2014. Concerns about misinterpretation of recent scientific data implicating dromedary camels in epidemiology of Middle East respiratory syndrome (MERS). MBio 5:e1430-01414. 10.1128/mBio.01430-14.

Shi P, Su Y, Li R, Liang Z, Dong S, and Huang J. 2019. PEDV nsp16 negatively regulates innate immunity to promote viral proliferation. Virus research 265:57-66. 
525 Su S, Wong G, Shi W, Liu J, Lai AC, Zhou J, Liu W, Bi Y, and Gao GF. 2016. Epidemiology,

526

527

528

529

530

531

532

533

534

535

536

537

538

539

540

541

542

543

544

545

546 genetic recombination, and pathogenesis of coronaviruses. Trends in microbiology 24:490-502.

Tamura K, Nei M, and Kumar S. 2004. Prospects for inferring very large phylogenies by using the neighbor-joining method. Proceedings of the National Academy of Sciences 101:11030-11035.

Tao Y, Shi M, Chommanard C, Queen K, Zhang J, Markotter W, Kuzmin IV, Holmes EC, and Tong S. 2017. Surveillance of bat coronaviruses in Kenya identifies relatives of human coronaviruses NL63 and 229E and their recombination history. Journal of virology 91:e01953-01916.

Tazerji SS, Duarte PM, Rahimi P, Shahabinejad F, Dhakal S, Malik YS, Shehata AA, Lama J, Klein J, and Safdar M. 2020. Transmission of severe acute respiratory syndrome coronavirus 2 (SARS-CoV-2) to animals: an updated review. Journal of Translational Medicine 18:1-11.

Walls AC, Park Y-J, Tortorici MA, Wall A, McGuire AT, and Veesler D. 2020. Structure, function, and antigenicity of the SARS-CoV-2 spike glycoprotein. Cell 181:281-292.

Wan Y, Shang J, Graham R, Baric RS, and Li F. 2020. Receptor recognition by the novel coronavirus from Wuhan: an analysis based on decade-long structural studies of SARS coronavirus. Journal of virology 94(7). DOI: 10.1128/JVI.00127-20

Wong MC, Cregeen SJJ, Ajami NJ, and Petrosino JF. 2020. Evidence of recombination in coronaviruses implicating pangolin origins of nCoV-2019. BioRxiv. doi: $10.1101 / 2020.02 .07 .939207$. 
547 Wu F, Zhao S, Yu B, Chen Y-M, Wang W, Song Z-G, Hu Y, Tao Z-W, Tian J-H, and Pei Y-Y.

548

549

550

551

552

553

554

555

556

557

558

559

560

561

562

563

564

565

566

567

568

569

2020. A new coronavirus associated with human respiratory disease in China. nature 579:265-269.

Yan R, Zhang Y, Li Y, Xia L, Guo Y, and Zhou Q. 2020. Structural basis for the recognition of SARS-CoV-2 by full-length human ACE2. Science 367:1444-1448.

Yao H, Lu X, Chen Q, Xu K, Chen Y, Cheng L, and Li L. 2020. Patient-derived mutations impact pathogenicity of SARS-CoV-2. medRxiv. Cell 23. doi: https://doi.org/10.1101/2020.04.14.20060160.

Ye Z-W, Yuan S, Yuen K-S, Fung S-Y, Chan C-P, and Jin D-Y. 2020. Zoonotic origins of human coronaviruses. International journal of biological sciences 16:1686-1697.

Zeng Z, Deng F, Shi K, Ye G, Wang G, Fang L, Xiao S, Fu Z, and Peng G. 2018. Dimerization of coronavirus nsp9 with diverse modes enhances its nucleic acid binding affinity. Journal of virology 92:e0692 - 00618.

Zhao X, Chen D, Szabla R, Zheng M, Li G, Du P, Zheng S, Li X, Song C, Li R, Guo J-T, Junop M, Zeng H, and Lin H. 2020. Broad and Differential Animal Angiotensin-Converting Enzyme 2 Receptor Usage by SARS-CoV-2. Journal of virology 94:e00940-00920. 10.1128/jvi.00940-20

Zhou P, Yang X-L, Wang X-G, Hu B, Zhang L, Zhang W, Si H-R, Zhu Y, Li B, and Huang C-L. 2020. A pneumonia outbreak associated with a new coronavirus of probable bat origin. nature 579:270-273.

Zhu X, Wang D, Zhou J, Pan T, Chen J, Yang Y, Lv M, Ye X, Peng G, and Fang L. 2017. Porcine deltacoronavirus nsp5 antagonizes type I interferon signaling by cleaving STAT2. Journal of virology 91:e0003-00017. 
570 Zou L, Ruan F, Huang M, Liang L, Huang H, Hong Z, Yu J, Kang M, Song Y, and Xia J. 2020.

571 SARS-CoV-2 viral load in upper respiratory specimens of infected patients. New England

$572 \quad$ Journal of Medicine 382:1177-1179.

573 


\section{Figure 1}

Phylogenetic tree of 40 SARS-CoV-2 genomes from animals and humans.

Each sequence is reported by the accession number, host, and geographic region (country). Different clades are labelled and highlighted differently. The tree was constructed in IQ-TREE using the maximum likelihood method, ModelFinder, and ultrafast bootstrap approximation (1000 replicates). The tree is rooted on midpoint. Branch lengths are measured in the number of substitutions per site. The percentage of replicate trees in which the associated viruses clustered together in the bootstrap test is represented by the numbers above the branches. Bootstrap values less than $50 \%$ are not shown. 


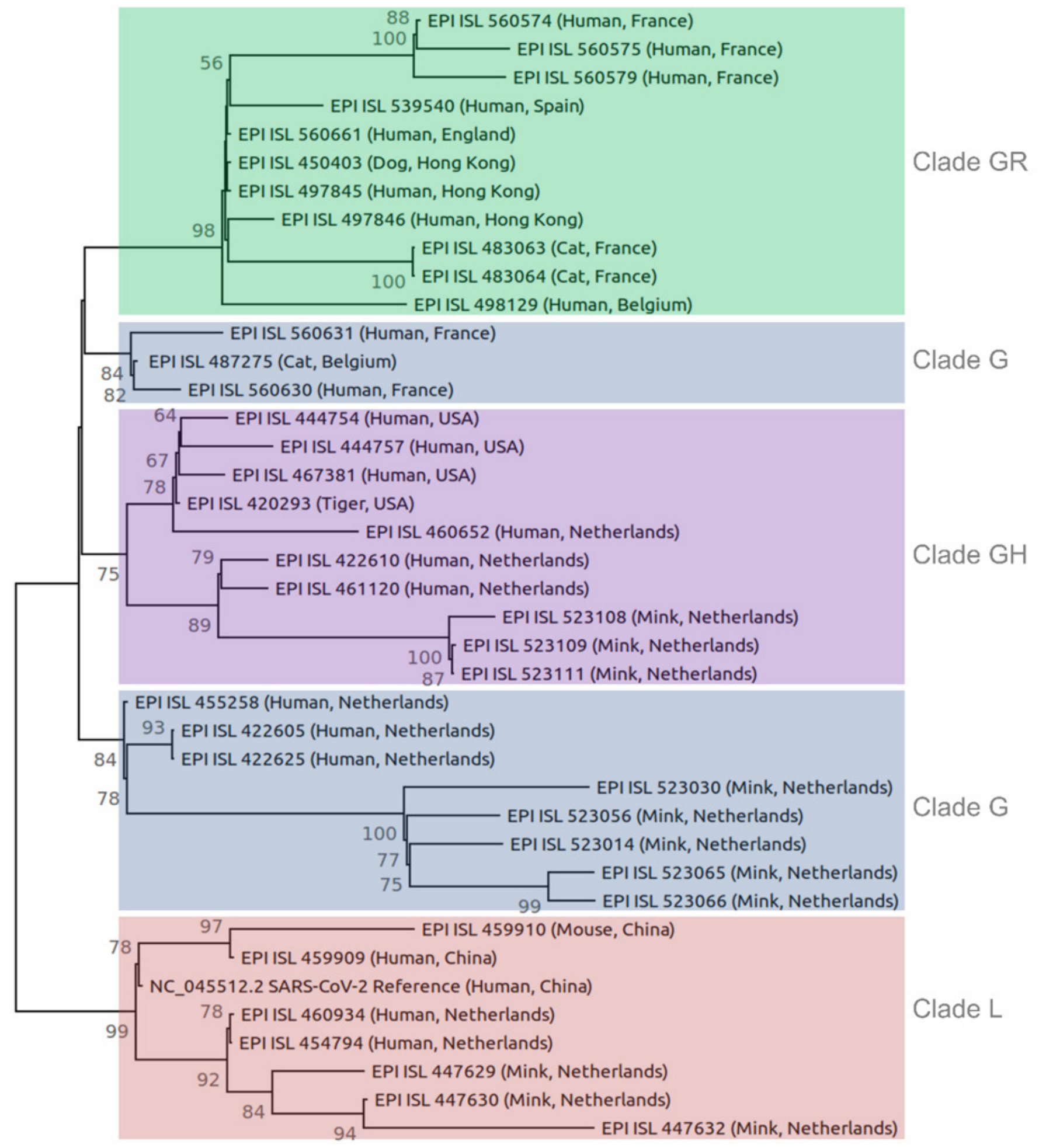

0.00010 


\section{Figure 2}

Map of SARS-CoV-2 spike protein structure.

This includes $\mathrm{N}$-terminal end $(\mathrm{NH} 2)$ to the $\mathrm{C}$-terminal end $(\mathrm{COOH})$, the signal peptide $(\mathrm{SP}), \mathrm{N}$ terminal domain (NTD), receptor-binding domain (RBD), receptor-binding motif (RBM), fusion peptide (FP), heptad repeat 1 (HR1), heptad repeat 2 (HR2), transmembrane domain (TM), and intracellular domain (IC). The spike protein consists of two subunits: S1 and S2 that are cleaved at the furin cleavage site. The differences in the spike amino acid sequences from animal isolates compared to SARS-CoV-2 reference (Wuhan-Hu-1 isolate), pangolin coronavirus MP789, and bat coronavirus RaTG13 are marked by the red rectangles. The multiple sequence alignment is presented for the RBM (bottom) and the furin cleavage site (top). 
SARS-COV-2 Reference SARS-COV-2 Cat SARS-COV-2 Dog 02-02756 SARS-COV-2 Mink NB01 01KS SARS-CoV-2 Mink NB02 07KS SARS-COV-2 Mink NB03 index SARS-COV-2 Mink NBO4 index SARS-COV-2 Mink NB-EMC-1-13 SARS-COV-2 Mink NB-EMC-23-1 SARS-COV-2 Mouse SARS-COV-2 Tiger Pangolin CoV MP789 Bat CoV RaTG13

\section{Furin cleavage site}

:

$\hat{6}:$

$\downarrow$ :

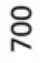

욱

PIGAGICASY RTQTNSPRRARSVASOSI IAYTMSLGAENSVAYSN

PIGAGICASYQTQTNSPRRARSVA SQSI IAYTMSLGAENSVAYS

PIGAGICASYQTQTNSPRRARSVA SQS IAYTMSLGAENSVAYS

PIGAGICASYQTQTNSPRRARSVASQSI IAYTMSLGAENSVAYS

PIGAGICASYQTQTNSPRRARSVA SOS IAYTMSLGAENSVAYS

PIGAGICASYQTQTNSPRRARSVA SQS IAYTMSLGAENSVAYS

PIGAGICASYQTQTNSPRRARSVASQSI IAYTMSLGAENSVAYS

PIGAGICASYQTQTNSPRRARSVA SQS I IAYTMSLGAENSVAYS

PIGAGICASYQTQTNSPRRARSVASQS IAYTMSLGAENSVAYS

PIGAGICASY-----SPRRARSVASQS I IAYTMSLGAENSVAYS

PIGAGICASYQTQTNSPRRARSVASQSI IAYTMSLGAENSVAYS

PIGAGICASYQTQTNS----RSVSSQAIIAYTMSLGAENSVAYA

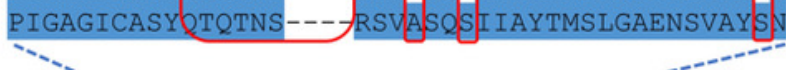

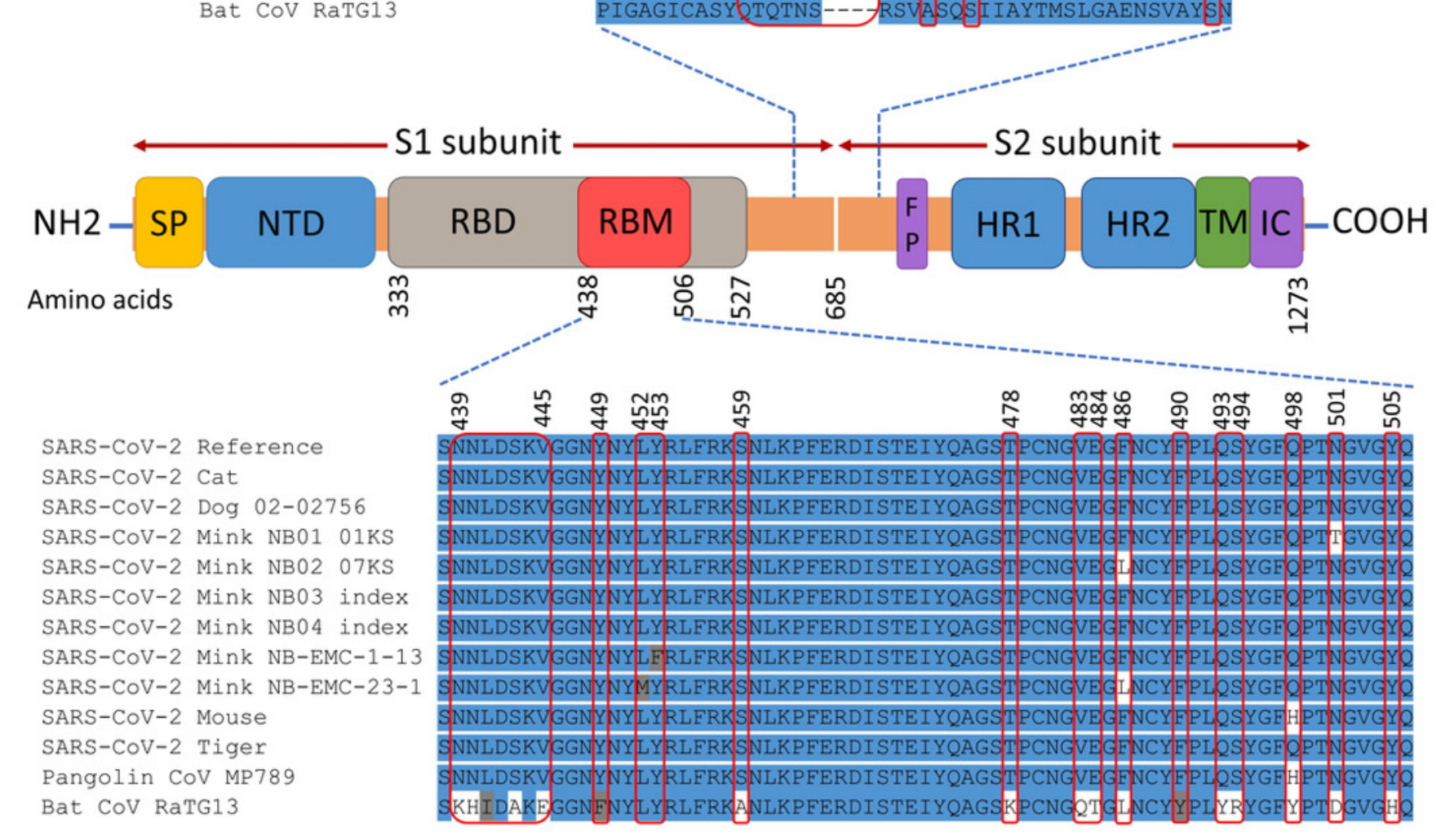




\section{Figure 3}

Amino acid substitutions in the receptor-binding motif (RBM) of SARS-CoV-2 S protein from animal isolates.

Only monomeric partial structure of $\mathrm{S}$ protein is shown where the receptor-binding domain (RBD) is purple, RBM is blue, and the substitution sites are red. This structure is based on Protein Data Bank (PDB) reference structure 6ZB4. In each mutation site, the side chains of the amino acid residues are shown for normal (A) and mutated (B) RBM. 

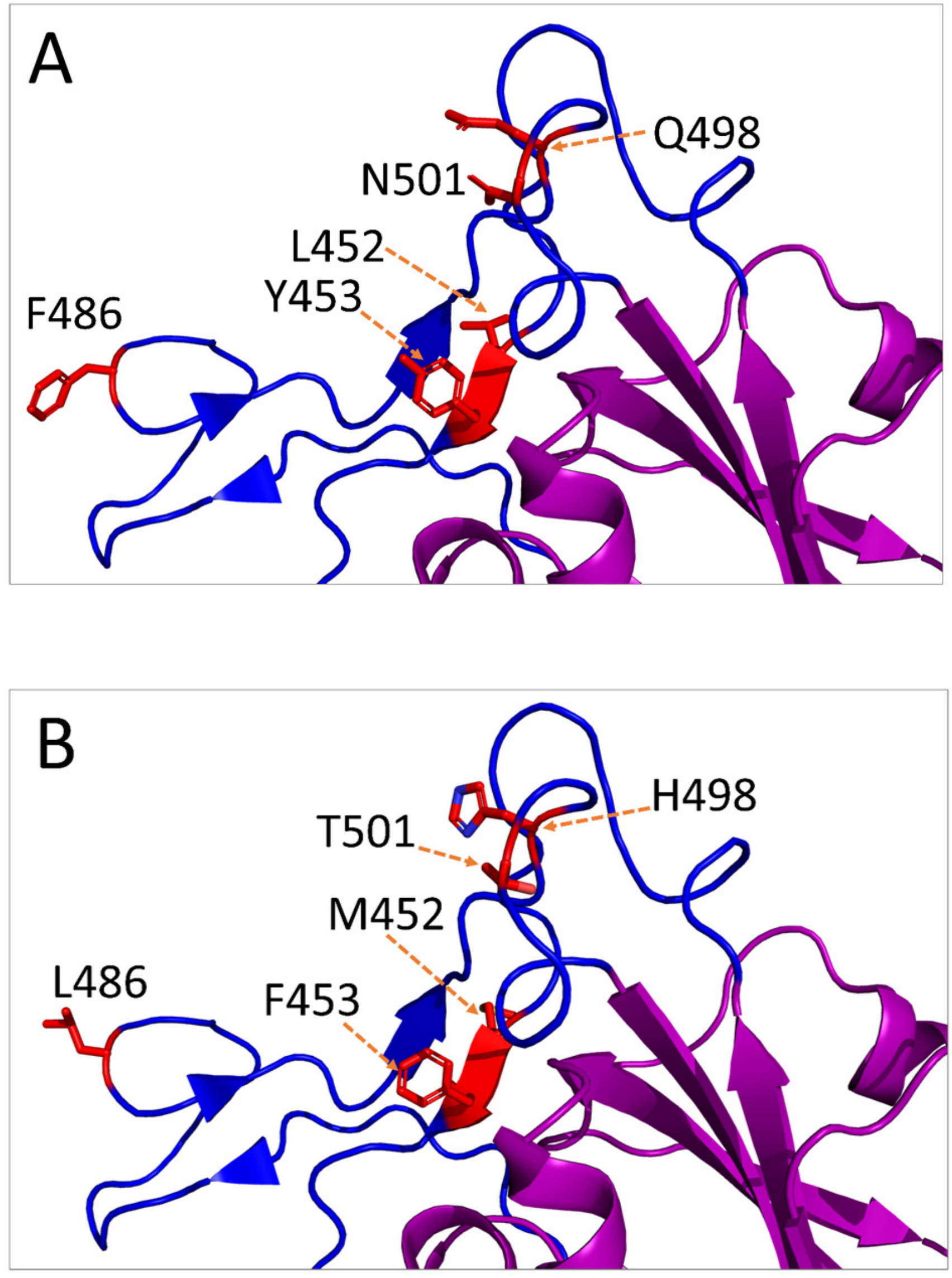


\section{Table $\mathbf{1}$ (on next page)}

Amino acid substitutions in the non-structural proteins encoded by orflab gene of SARSCoV-2 isolated from animals compared to humans.

(A) orflab=open reading frame $1 \mathrm{ab} ; \mathrm{nsp}=$ non-structural protein. The numbers in brackets represent the percentage of genomes that contains the substitution. For example, the substitution of amino acid number 372 of nsp2 protein from $A$ to $V(A 372 V)$ in mink occurred in $46.3 \%$ of mink isolates. Percentages are reported for substitutions only. Substitutions that existed in less than $2 \%$ of the genomes are not reported. Unique mutations for an animal species are highlighted in yellow. 
1

\begin{tabular}{|c|c|c|c|c|c|c|c|c|}
\hline Gene $^{(A)}$ & $\begin{array}{l}\text { Amino acid } \\
\text { position }\end{array}$ & $\begin{array}{c}\text { SARS-CoV-2 } \\
\text { Reference }\end{array}$ & Cat & Dog & Mink & Mouse & Tiger & Human \\
\hline \multirow{7}{*}{$\mathrm{nsp} 2$} & 265 & $\mathrm{~T}$ & I $(20.0)$ & $\mathrm{T}$ & $\mathrm{T}$ & $\mathrm{T}$ & $\mathrm{I}(100.0)$ & $\mathrm{T}$ or I \\
\hline & 352 & $\mathrm{E}$ & $\mathrm{E}$ & $E$ & $\mathrm{Q}(2.7)$ & $\mathrm{E}$ & $\mathrm{E}$ & $\mathrm{E}$ \\
\hline & 372 & A & $\mathrm{A}$ & $\mathrm{A}$ & $\mathrm{V}(46.3)$ & $\mathrm{A}$ & $\mathrm{A}$ & $\mathrm{A}$ \\
\hline & 388 & $\mathrm{H}$ & $Y(40.0)$ & $\mathrm{H}$ & $\mathrm{H}$ & $\mathrm{H}$ & $\mathrm{H}$ & $\mathrm{H}$ \\
\hline & 398 & $\mathrm{R}$ & $\mathrm{R}$ & $\mathrm{R}$ & $\mathrm{C}(25.2)$ & $\mathrm{R}$ & $\mathrm{R}$ & $\mathrm{R}$ \\
\hline & 405 & A & A & $\mathrm{A}$ & $\mathrm{T}(4.8)$ & $\mathrm{A}$ & $\mathrm{A}$ & $\mathrm{A}$ \\
\hline & 743 & $\mathrm{E}$ & $\mathrm{E}$ & $\mathrm{E}$ & $\mathrm{V}(2.7)$ & $\mathrm{E}$ & $\mathrm{E}$ & $\mathrm{E}$ \\
\hline \multirow{9}{*}{ nsp3 } & 953 & $\mathrm{D}$ & $\mathrm{Y}(20.0)$ & $\mathrm{D}$ & $\mathrm{D}$ & $\mathrm{D}$ & $\mathrm{D}$ & $\mathrm{D}$ \\
\hline & 996 & $\mathrm{D}$ & $\mathrm{D}$ & $\mathrm{D}$ & $\mathrm{Y}(20.7)$ & $\mathrm{D}$ & $\mathrm{D}$ & D or $\mathrm{Y}$ \\
\hline & 1052 & $\mathrm{~V}$ & I (40.0) & $\mathrm{V}$ & $\mathrm{V}$ & $\mathrm{V}$ & $\mathrm{V}$ & $\mathrm{V}$ \\
\hline & 1096 & $\mathrm{P}$ & $\mathrm{P}$ & $\mathrm{P}$ & $\mathrm{L}(3.4)$ & $\mathrm{P}$ & $\mathrm{P}$ & $\mathrm{P}$ \\
\hline & 1113 & $\mathrm{H}$ & $\mathrm{H}$ & $\mathrm{H}$ & $\mathrm{Y}(4.1)$ & $\mathrm{H}$ & $\mathrm{H}$ & $\mathrm{H}$ \\
\hline & 1202 & $\mathrm{~K}$ & $\mathrm{~N}(40.0)$ & $\mathrm{K}$ & $\mathrm{K}$ & $\mathrm{K}$ & $\mathrm{K}$ & $\mathrm{K}$ \\
\hline & 1568 & I & I & $\mathrm{I}$ & $\mathrm{V}(10.9)$ & $\mathrm{I}$ & $\mathrm{I}$ & $\mathrm{I}$ \\
\hline & 1588 & $\mathrm{M}$ & $\mathrm{M}$ & $\mathrm{M}$ & $\mathrm{K}(20.0)$ & $\mathrm{M}$ & $\mathrm{M}$ & $\mathrm{M}$ \\
\hline & 2101 & $\mathrm{D}$ & $\mathrm{D}$ & $\mathrm{G}(50.0)$ & $\mathrm{D}$ & $\mathrm{D}$ & $\mathrm{D}$ & $\mathrm{D}$ \\
\hline \multirow{2}{*}{ nsp4 } & 3076 & $\mathrm{H}$ & $\mathrm{H}$ & $\mathrm{H}$ & $\mathrm{H}(100.0)$ & $\mathrm{Y}$ & $\mathrm{H}$ & $\mathrm{H}$ or $\mathrm{Y}$ \\
\hline & 3233 & $\mathrm{H}$ & $\mathrm{H}$ & $\mathrm{Y}(50.0)$ & $\mathrm{H}$ & $\mathrm{H}$ & $\mathrm{H}$ & $\mathrm{H}$ or $\mathrm{Y}$ \\
\hline \multirow{2}{*}{ nsp5 } & 3512 & $\mathrm{I}$ & $\mathrm{T}(20.0)$ & $\mathrm{I}$ & I & $\mathrm{I}$ & $\mathrm{I}$ & I \\
\hline & 3522 & $\mathrm{I}$ & $\mathrm{I}$ & $\mathrm{I}$ & $\mathrm{V}(5.4)$ & $\mathrm{I}$ & $\mathrm{I}$ & $\mathrm{I}$ \\
\hline \multirow{2}{*}{ nsp6 } & 3606 & $\mathrm{~L}$ & $\mathrm{~L}$ & $\mathrm{~L}$ & $\mathrm{~F}(12.2)$ & $\mathrm{L}$ & $\mathrm{L}$ & L or $F$ \\
\hline & 3615 & $\mathrm{~A}$ & $\mathrm{~A}$ & $\mathrm{~A}$ & $\mathrm{~V}(25.9)$ & $\mathrm{A}$ & $\mathrm{A}$ & A or $\mathrm{V}$ \\
\hline nsp9 & 4177 & $\mathrm{G}$ & $\mathrm{G}$ & $\mathrm{G}$ & $\begin{array}{l}\mathrm{E}(28.6) \\
\mathrm{R}(23.8)\end{array}$ & $\mathrm{G}$ & G & $\mathrm{G}$ \\
\hline nsp10 & 4377 & $\mathrm{~K}$ & $\mathrm{E}(16.7)$ & $\mathrm{K}$ & $\mathrm{K}$ & $\mathrm{K}$ & $\mathrm{K}$ & $\mathrm{K}$ \\
\hline \multirow{4}{*}{ nsp12 } & 4418 & $\mathrm{~T}$ & $\mathrm{I}(40.0)$ & $\mathrm{T}$ & $\mathrm{T}$ & $\mathrm{T}$ & $\mathrm{T}$ & $\mathrm{T}$ \\
\hline & 4588 & $\mathrm{M}$ & $\mathrm{M}$ & $\mathrm{M}$ & $\mathrm{I}(2.7)$ & $\mathrm{M}$ & $\mathrm{M}$ & $\mathrm{M}$ \\
\hline & 4715 & $\mathrm{P}$ & L (100.0) & $\mathrm{L}(50.0)$ & $\mathrm{L}(74.8)$ & $\mathrm{P}$ & $\mathrm{L}$ & $\mathrm{P}$ or $\mathrm{L}$ \\
\hline & 5195 & $\mathrm{~T}$ & $\mathrm{~T}$ & $\mathrm{~T}$ & I (4.1) & $\mathrm{T}$ & $\mathrm{T}$ & $\mathrm{T}$ \\
\hline \multirow{3}{*}{ nsp13 } & 5582 & I & I & $\mathrm{I}$ & $\mathrm{V}(6.1)$ & $\mathrm{I}$ & $\mathrm{I}$ & I \\
\hline & 5716 & $\mathrm{R}$ & $\mathrm{R}$ & $\mathrm{R}$ & $\mathrm{C}(25.2)$ & $\mathrm{R}$ & $\mathrm{R}$ & $\mathrm{R}$ or $\mathrm{C}$ \\
\hline & 5770 & $\mathrm{~A}$ & $\mathrm{~A}$ & $\mathrm{~A}$ & $\mathrm{D}(3.0)$ & $\mathrm{A}$ & $\mathrm{A}$ & $\mathrm{A}$ \\
\hline nsp15 & 6544 & A & $\mathrm{A}$ & A & $\mathrm{T}(2.8)$ & $\mathrm{A}$ & $\mathrm{A}$ & $\mathrm{A}$ \\
\hline
\end{tabular}

2 


\section{Table 2 (on next page)}

Amino acid substitutions in the structural proteins of SARS-CoV-2 isolated from animals compared to humans.

(A) $\mathrm{S}=$ spike; ${ }^{(\mathrm{B})} \mathrm{M}=$ matrix; ${ }^{(\mathrm{C})} \mathrm{N}=$ nucleocapsid. The numbers in brackets represent the percentage of genomes that contains the substitution. For example, the substitution of amino acid number 261 of S protein from G to D (G261D) in mink occurred in $4.8 \%$ of mink isolates. Percentages are reported for substitutions only. Substitutions that existed in less than $2 \%$ of the genomes are not reported. Unique mutations for an animal species are highlighted in yellow. No substitutions were detected in the envelope protein. 
1

\begin{tabular}{|c|c|c|c|c|c|c|c|c|}
\hline Gene & $\begin{array}{l}\text { Amino acid } \\
\text { position }\end{array}$ & $\begin{array}{l}\text { SARS-CoV-2 } \\
\text { Reference }\end{array}$ & Cat & Dog & Mink & Mouse & Tiger & Human \\
\hline \multirow{11}{*}{$\mathrm{S}^{(\mathrm{A})}$} & 8 & $\mathrm{~L}$ & $\mathrm{~L}$ & $\mathrm{~V}(50.0)$ & L & $\mathrm{L}$ & L & $\mathrm{L}$ or $\mathrm{V}$ \\
\hline & 261 & $\mathrm{G}$ & $\mathrm{G}$ & $\mathrm{G}$ & $\mathrm{D}(4.8)$ & $\mathrm{G}$ & $\mathrm{G}$ & $\mathrm{G}$ \\
\hline & 262 & $\mathrm{~A}$ & $\mathrm{~A}$ & $\mathrm{~A}$ & $\mathrm{~S}(5.4)$ & $\mathrm{A}$ & $\mathrm{A}$ & $\mathrm{A}$ \\
\hline & 367 & $\mathrm{~V}$ & $\mathrm{~V}$ & $\mathrm{~V}$ & $\mathrm{~F}(5.4)$ & $\mathrm{V}$ & $\mathrm{V}$ & $\mathrm{V}$ \\
\hline & 452 & $\mathrm{~L}$ & $\mathrm{~L}$ & $\mathrm{~L}$ & $\mathrm{M}(10.2)$ & $\mathrm{L}$ & $\mathrm{L}$ & $\mathrm{L}$ \\
\hline & 453 & $\mathrm{Y}$ & $\mathrm{Y}$ & $\mathrm{Y}$ & $\mathrm{F}(23.8)$ & $\mathrm{Y}$ & $\mathrm{Y}$ & $\mathrm{Y}$ \\
\hline & 486 & $\mathrm{~F}$ & $\mathrm{~F}$ & $\mathrm{~F}$ & $\mathrm{~L}(17.0)$ & $\mathrm{F}$ & $\mathrm{F}$ & $\mathrm{F}$ \\
\hline & 498 & Q & Q & Q & $\mathrm{Q}$ & $\mathrm{H}(100.0)$ & $\mathrm{Q}$ & $\mathrm{Q}$ \\
\hline & 501 & $\mathrm{~N}$ & $\mathrm{~N}$ & $\mathrm{~N}$ & $\mathrm{~T}(3.4)$ & $\mathrm{N}$ & $\mathrm{N}$ & $\mathrm{N}$ or $\mathrm{Y}$ \\
\hline & 614 & $\mathrm{D}$ & $\mathrm{G}(100.0)$ & $\mathrm{D}$ & $\mathrm{G}(74.8)$ & $\mathrm{D}$ & $\mathrm{G}$ & D or $G$ \\
\hline & 969 & $\mathrm{~N}$ & $\mathrm{~N}$ & $\mathrm{~N}$ & $\mathrm{~N}$ & S (100.0) & $\mathrm{N}$ & $\mathrm{N}$ \\
\hline \multirow{2}{*}{$\mathrm{M}^{(\mathrm{B})}$} & 3 & $\mathrm{D}$ & $\mathrm{D}$ & $\mathrm{D}$ & $\mathrm{G}(2.7)$ & $\mathrm{D}$ & $\mathrm{D}$ & D or $G$ \\
\hline & 175 & $\mathrm{~T}$ & $M(16.7)$ & $\mathrm{T}$ & $\mathrm{T}$ & $\mathrm{T}$ & $\mathrm{T}$ & $\mathrm{T}$ \\
\hline \multirow{6}{*}{$\mathrm{N}^{(\mathrm{C})}$} & 41 & $\mathrm{R}$ & $\mathrm{R}$ & $\mathrm{R}$ & $\mathrm{L}(2.7)$ & $\mathrm{R}$ & $\mathrm{R}$ & $\mathrm{R}$ \\
\hline & 80 & $\mathrm{P}$ & $\mathrm{P}$ & $\mathrm{P}$ & L (2.7) & $\mathrm{P}$ & $\mathrm{P}$ & $\mathrm{P}$ \\
\hline & 199 & $\mathrm{P}$ & $\mathrm{P}$ & $\mathrm{P}$ & $\mathrm{Q}(2.7)$ & $\mathrm{P}$ & $\mathrm{P}$ & $\mathrm{P}$ \\
\hline & 203 & $\mathrm{R}$ & $\mathrm{K}(60.0)$ & $\mathrm{R}$ & $\mathrm{R}$ & $\mathrm{R}$ & $\mathrm{R}$ & $\mathrm{R}$ or $\mathrm{K}$ \\
\hline & 204 & $\mathrm{G}$ & $\mathrm{R}(60.0)$ & $\mathrm{G}$ & $\mathrm{G}$ & $\mathrm{G}$ & $\mathrm{G}$ & $\mathrm{G}$ or $\mathrm{R}$ \\
\hline & 247 & $\mathrm{~T}$ & I (16.7) & $\mathrm{T}$ & $\mathrm{T}$ & $\mathrm{T}$ & $\mathrm{T}$ & $\mathrm{T}$ \\
\hline
\end{tabular}

2 


\section{Table 3 (on next page)}

Amino acid substitutions in the non-structural proteins encoded by orf3a and orf6 genes of SARS-CoV-2 isolated from animals compared to humans.

${ }^{(A)}$ orf3a =open reading frame $3 a,{ }^{(B)} n s 3 a$, non-structural protein $3 a$. The numbers in brackets represent the percentage of genomes that contains the substitution. For example, the substitution of amino acid number 219 of ns3a protein (encoded by orf3a) from $L$ to $V$ (L219V) in mink occurred in $25.6 \%$ of mink isolates. Percentages are reported for substitutions only. Substitutions that existed in less than $2 \%$ of the genomes are not reported. Unique mutations for an animal species are highlighted in yellow. 
1

\begin{tabular}{|c|c|c|c|c|c|c|c|c|}
\hline Gene & $\begin{array}{c}\text { Amino acid } \\
\text { position }\end{array}$ & $\begin{array}{c}\text { SARS-CoV-2 } \\
\text { Reference }\end{array}$ & Cat & Dog & Mink & Mouse & Tiger & Human \\
\hline \multirow[t]{6}{*}{$\operatorname{orf3} \mathrm{a}^{(\mathrm{A})}$} & 57 & Q & Q & Q & $\mathrm{H}(25.9)$ & Q & $\mathrm{H}$ & $\mathrm{Q}$ or $\mathrm{H}$ \\
\hline & 182 & $\mathrm{H}$ & $\mathrm{H}$ & $\mathrm{H}$ & $\begin{array}{l}\mathrm{L}(3.4) \\
\mathrm{Y}(22.4) \\
\end{array}$ & $\mathrm{H}$ & $\mathrm{H}$ & $\mathrm{H}$ \\
\hline & 219 & $\mathrm{~L}$ & $\mathrm{~L}$ & $\mathrm{~L}$ & $\mathrm{~V}(25.6)$ & $\mathrm{L}$ & $\mathrm{L}$ & $\mathrm{L}$ \\
\hline & 224 & $\mathrm{G}$ & $\mathrm{G}$ & $\mathrm{G}$ & $\mathrm{C}(2.7)$ & $\mathrm{G}$ & $\mathrm{G}$ & $\mathrm{G}$ \\
\hline & 229 & $\mathrm{~T}$ & $\mathrm{~T}$ & $\mathrm{~T}$ & I (16.3) & $\mathrm{T}$ & $\mathrm{T}$ & $\mathrm{T}$ \\
\hline & 251 & $\mathrm{G}$ & $\mathrm{G}$ & $\mathrm{V}(50.0)$ & $\mathrm{G}$ & $\mathrm{G}$ & $\mathrm{G}$ & $\mathrm{G}$ or $\mathrm{V}$ \\
\hline \multirow{2}{*}{$\operatorname{orf6}^{(\mathrm{B})}$} & 20 & $\mathrm{R}$ & $\mathrm{R}$ & $\mathrm{R}$ & $\mathrm{S}(10.2)$ & $\mathrm{R}$ & $\mathrm{R}$ & $\mathrm{R}$ \\
\hline & 23 & $\mathrm{~K}$ & $\mathrm{~K}$ & $\mathrm{~K}$ & $\mathrm{~S}(2.0)$ & $\mathrm{K}$ & $\mathrm{K}$ & $\mathrm{K}$ \\
\hline
\end{tabular}

2

3

4 